\title{
Differential Expression Patterns of Lynx Proteins and Involvement of Lynx1 in Prepulse Inhibition
}

\author{
Yasmine Sherafat ${ }^{1}$, Edison Chen ${ }^{1}$, Valeria Lallai', Malia Bautista ${ }^{1}$, James P. Fowler ${ }^{1}$, \\ Yen-Chu Chen ${ }^{1}$, Julie Miwa ${ }^{2}$ and Christie D. Fowler ${ }^{1 *}$ \\ ${ }^{1}$ Department of Neurobiology and Behavior, University of California, Irvine, Irvine, CA, United States, ${ }^{2}$ Department \\ of Biological Sciences, Lehigh University, Bethlehem, PA, United States
}

OPEN ACCESS

Edited by: Timothy J. Jarome,

Virginia Tech, United States

Reviewed by:

Maarten Van Den Buuse,

La Trobe University, Australia

Jaekyoon Kim

The University of lowa, United States

*Correspondence: Christie D. Fowler cdfowler@uci.edu

Specialty section:

This article was submitted to

Learning and Memory,

a section of the journal

Frontiers in Behavioral Neuroscience

Received: 14 May 2021 Accepted: 29 September 2021

Published: 03 November 2021

Citation

Sherafat Y, Chen E, Lallai V, Bautista M, Fowler JP, Chen Y-C,

Miwa J and Fowler CD (2021)

Differential Expression Patterns of Lynx Proteins and Involvement

of Lynx1 in Prepulse Inhibition.

Front. Behav. Neurosci. 15:703748.

doi: 10.3389/fnbeh.2021.703748
Negative allosteric modulators, such as lynx1 and lynx2, directly interact with nicotinic acetylcholine receptors ( $\mathrm{nAChRs)}$. The $\mathrm{nAChRs}$ are integral to cholinergic signaling in the brain and have been shown to mediate different aspects of cognitive function. Given the interaction between lynx proteins and these receptors, we examined whether these endogenous negative allosteric modulators are involved in cognitive behaviors associated with cholinergic function. We found both cell-specific and overlapping expression patterns of lynx 1 and lynx 2 mRNA in brain regions associated with cognition, learning, memory, and sensorimotor processing, including the prefrontal cortex (PFC), cingulate cortex, septum, hippocampus, amygdala, striatum, and pontine nuclei. Since lynx proteins are thought to play a role in conditioned associations and given the expression patterns across brain regions, we first assessed whether lynx knockout mice would differ in a cognitive flexibility task. We found no deficits in reversal learning in either the lynx $1^{-/-}$or lynx $2^{-/-}$knockout mice. Thereafter, sensorimotor gating was examined with the prepulse inhibition (PPI) assessment. Interestingly, we found that both male and female lynx $1^{-/-}$mice exhibited a deficit in the PPI behavioral response. Given the comparable expression of lynx2 in regions involved in sensorimotor gating, we then examined whether removal of the lynx2 protein would lead to similar behavioral effects. Unexpectedly, we found that while male lynx $2^{-/-}$mice exhibited a decrease in the baseline startle response, no differences were found in sensorimotor gating for either male or female lynx $2^{-/-}$mice. Taken together, these studies provide insight into the expression patterns of lynx1 and lynx2 across multiple brain regions and illustrate the modulatory effects of the lynx1 protein in sensorimotor gating.

Keywords: nicotinic acetylcholin receptor (nAChR), cholinergic signaling, sensory gating, learning and memory, cognitive flexibility

\section{INTRODUCTION}

The cholinergic system controls a variety of complex cognitive processes, such as attention, sensorimotor gating, cognitive flexibility, reinforcement, learning, and memory (Court et al., 1999; Miwa et al., 2006, 2011; Tekinay et al., 2009; Zhang et al., 2010; de la Salle et al., 2013; Freitas et al., 2013; Chen et al., 2018, 2020; Solari and Hangya, 2018; Anderson et al., 2020; Sherafat et al., 2021). 
Integral to the cholinergic system are the nicotinic acetylcholine receptors (nAChRs). Binding of the endogenous agonist acetylcholine induces a conformational change that opens the channel, allowing for the influx of $\mathrm{Na}^{+}$and $\mathrm{Ca}^{2+}$ and the efflux of $\mathrm{K}^{+}$, followed by a desensitized state (Lipsius, 1982; Fuentealba et al., 2004). The nAChRs exhibit various allosteric binding sites, which allow for modulation of the pharmacokinetics associated with receptor activation and desensitization (Le Novere et al., 2002). The lynx1 and lynx2 proteins are classified as negative allosteric modulators of the cholinergic system through their actions in reducing the activity of the nAChRs in the presence of an agonist (Ibanez-Tallon et al., 2002; Kobayashi et al., 2014; Nichols et al., 2014; George et al., 2017). Therefore, lynx proteins dampen the cholinergic system's activity, which has been proposed to subsequently underlie changes in memory, learning, and plasticity (Miwa et al., 2006; Morishita et al., 2010).

At the cell membrane, the lynx proteins are mainly thought to associate with nAChRs while anchored to the membrane through a GPI link (George et al., 2017), but depending on the isoform, lynx proteins may also be released into the extracellular space to exert actions on the membrane surface (Dessaud et al., 2006; Holford et al., 2009; Tekinay et al., 2009; Bychkov et al., 2019; Dong et al., 2020). In addition to their actions on membrane-bound nAChRs, lynx proteins may also affect the trafficking of nAChR subunits to the membrane via association in the endoplasmic reticulum (Nichols et al., 2014; Miwa et al., 2019). The ability of lynx proteins to modulate these cholinergic processes through both extracellular and intracellular mechanisms has important implications for cognitive aspects of neurological and psychiatric diseases (Smith et al., 2018; Artoni et al., 2020; Miwa, 2020). Indeed, prior studies in mice lacking the lynx1 (lynx $\left.1^{-/-}\right)$and lynx2 $\left(\operatorname{lyn} \times 2^{-/-}\right)$ proteins have provided foundational insights into the function of these endogenous modulators. For instance, removal of lynx1 augments cholinergic processing, leading to enhanced associative learning in a fear conditioning task and expanded critical period for visual plasticity (Miwa et al., 2006; Morishita et al., 2010; Bukhari et al., 2015; Sajo et al., 2016). Removal of lynx2 has been shown to increase anxiety associated behavior and decrease social interaction (Dessaud et al., 2006; Miwa et al., 2012). While the actions of the lynx proteins are considered to be inhibitory to excitatory signaling, it is important to note that the cell-type specific pattern of expression may lead to opposing effects. For example, expression on GABAergic cells leads to net inhibition of the inhibitory neurons, thereby increasing gain modulation (Disney et al., 2007; Morishita et al., 2010). However, the extent of modulation imposed by the lynx proteins leading to downstream behavioral effects has not yet been fully elucidated.

Prepulse inhibition (PPI) is an operational measure of sensorimotor gating that is disrupted in many neurological and psychiatric disorders, including Schizophrenia, Huntington's Disease, Alzheimer's Disease, and dementia (Swerdlow et al., 1995; Bakshi and Geyer, 1998; Takeuchi et al., 2011; Kucinski et al., 2012). Sensorimotor gating is a feature of the nervous system in adjusting a response to consequent stimuli based on prior experiences (Golubic et al., 2019). The modulation of the neural response induced by stimuli is a cognitive ability that is considered to be essential to maintaining function in everyday life (Golubic et al., 2019). Given that the PPI protocol can be implemented in both rodent and human models, this assessment is characterized as having translational relevance (Swerdlow et al., 1999), and interestingly, the septum, pedunculopontine tegmental nucleus (PPTg), pontine reticular nucleus (PnC), nucleus accumbens (NAcc), and amygdala have been shown to regulate PPI-relevant sensorimotor and cognitive processing across species (Swerdlow and Geyer, 1993; Swerdlow et al., 1995, 2007; Wan and Swerdlow, 1997; Bakshi and Geyer, 1998; Schell et al., 2000; Baldan Ramsey et al., 2011; Takeuchi et al., 2011; Kucinski et al., 2012; Kiziltan et al., 2018; Jin et al., 2019; Sullivan et al., 2019; Cano et al., 2021). For instance, optogenetic activation of the cholinergic neurons in the PPTg has been shown to increase prepulse facilitation (Azzopardi et al., 2018). Given that studies have implicated multiple brain regions in PPI, this highlights the dynamic complexity of brain circuit signaling to mediate such a response.

Reversal learning is another cognitive process that refers to the ability to quickly adjust behavior in the face of changing situations (Izquierdo et al., 2017). Studies have found that brain regions such as the medial prefrontal cortex (PFC), striatum, hippocampus, and cingulate cortex play an important role in reversal learning (Castane et al., 2010; Dalton et al., 2016; Vila-Ballo et al., 2017; Stolyarova et al., 2019). For example, chemogenetic inhibition of the cingulate cortex affects confidence enhanced reversal learning (Stolyarova et al., 2019). Similar to PPI, reversal learning is disrupted in a variety of neurological and psychiatric disorders, including substance abuse, obsessive compulsive disorder, Parkinson's disease, and Schizophrenia (Dargis et al., 2017; Tezcan et al., 2017; Bechard et al., 2018; Kleinmans and Bilkey, 2018; Levy-Gigi et al., 2019). In a reversal learning paradigm, subjects are trained to discriminate between stimuli, one of which is rewarded when chosen. After the discrimination has been learned, the outcomes associated with the two stimuli are reversed and subjects are tested on their ability to appropriately adjust their behavior (Izquierdo et al., 2017). This classical reversal learning paradigm is also translationally relevant, as it has been used in both humans and rodent models (Schoenbaum et al., 2000; Fellows and Farah, 2003).

In these studies, we first examined whether lynx1 and lynx2 were expressed in brain regions implicated in cognitive function. Based on our findings, we then focused our studies on mouse models with targeted deletion of the Lynx1 gene or the Lynx2 gene via homologous recombination (Miwa et al., 2006; Tekinay et al., 2009). Since lynx1 has been shown to be involved in cue-associated conditioning, we first assessed male and female lynx1 knockout $\left(\operatorname{lyn} \times 1^{-/-}\right)$and wildtype $\left(\operatorname{lynx} 1^{+/+}\right)$mice in a cued reversal learning task. Next, we performed this reversal assessment in the male and female lynx $2^{-/-}$and lynx $2^{+/+}$mice. Thereafter, we examined whether the male and female lynx $1^{-/-}$and $l y n \times 1^{+/+}$mice differ in their baseline startle response and sensorimotor gating for PPI. Finally, given the similar expression of lynx2 in regions mediating sensorimotor gating, we also examined male and female lynx $2^{-/-}$and lynx $2^{+/+}$mice in the PPI assessment. Together, our data suggest differential roles of lynx1 and lynx2 
proteins in startle reactivity and sensorimotor gating responses in males and females.

\section{MATERIALS AND METHODS}

\section{Mice}

Male and female adult mice on a C57BL/6J background with null mutations in the Lynx1 or Lynx2 gene and their respective wildtype littermates were bred in our animal facilities. Mice were 8-15 weeks of age, group housed and maintained in a humidityand temperature- controlled $\left(22^{\circ} \mathrm{C}\right)$ vivarium on a reverse 12 h: 12 h light: dark cycle. Prior to all behavioral assessments, mice were habituated in the room with the experimenter across 2 days, and behavioral tests were conducted during the active, dark phase of the light cycle. All procedures were conducted in strict accordance with the NIH Guide for the Care and Use of Laboratory Animals and approved by the University of California Irvine IACUC.

\section{Lynx1 and Lynx2 Genotyping}

At 21 days of age, pups were weaned, and tails were clipped for genetic analysis. Lynx1 littermates were genotyped with the following primers: Lynx1 WT Forward (CTGGAGTGCCACGTGTGTGCC), Lynx1 KO Forward (GCCAGCTTGGCGTGAAGTTCC), and Lynx1 WT/KO Reverse (CGTTTGAGTGGATCTGGCTTGGGG). The band for the lynx1 wildtype allele was detected at $470 \mathrm{bp}$ and for the lynx 1 knockout allele at $200 \mathrm{bp}$. Lynx2 littermates were genotyped with: Lynx $2 \mathrm{WT} / \mathrm{KO}$ Forward (CCACCGAATCTCCCAAATCC), Lynx2 KO Reverse (CCCTGGCAATTAACCCTAA), Lynx2 WT Reverse (TCCTCCACTACTCCCCTTTCTGAC). The band for the lynx2 wildtype allele was detected at $200 \mathrm{bp}$ and for the lynx2 knockout allele at $400 \mathrm{bp}$.

\section{RNAScope}

Brain tissue was examined to determine Lynx1 and Lynx2 mRNA expression in the PFC, cingulate cortex, septum, NAcc, striatum, amygdala, hippocampus, PPTg, and PnC. Male and female adult C57BL/6J wildtype ( $n=5$ per sex) were anesthetized with ketamine-xylazine and perfused through the ascending aorta with $0.9 \%$ saline followed by $4 \%$ paraformaldehyde in $0.1 \mathrm{M}$ $\mathrm{PBS}, \mathrm{pH}$ 7.4. Thereafter, brains were removed and postfixed for $2 \mathrm{~h}$ in paraformaldehyde, followed by cryoprotection in 30\% sucrose for $\sim 72 \mathrm{~h}$. Brain sections were cut on a cryostat at 35$\mu \mathrm{m}$ intervals. Three sections per brain region were analyzed for each subject. Afterward, brain tissue was processed for RNAscope Multiplex Fluorescent assay (Advanced Cell Diagnostics) as previously described (Sherafat et al., 2020). Briefly, sections were placed in an incubator for $30 \mathrm{~min}$ at $60^{\circ} \mathrm{C}$ then treated at $100^{\circ} \mathrm{C}$ for $6 \mathrm{~min}$ in target retrieval solution (Advanced Cell Diagnostics). Sections were dehydrated in 100\% ethanol and treated with protease (Advanced Cell Diagnostics, catalog \#322380). RNA hybridization probes included Lynx1 (Advanced Cell Diagnostics, catalog \# 449078) and Lynx2 (Advanced Cell Diagnostics, catalog \#447088-C2), which were labeled with Opal 520 and Opal 570 (PerkinElmer), respectively. Slides were then counterstained and cover slipped with Vectashield containing DAPI (Vector Laboratories) and imaged with a Leica fluorescence microscope.

\section{Reversal Learning}

Mice were assessed for reversal learning as previously described (Pushkin et al., 2019; Figure 4A). Subjects were mildly food restricted (85-90\% of their free feeding weight) and trained to press a lever in an operant chamber for $20 \mathrm{mg}$ food pellets (5TUM, Test Diet) under a fixed ratio 5, time-out $20 \mathrm{~s}$ (FR5TO20s) schedule of reinforcement. Each session was performed using 2 retractable levers ( 1 active, 1 inactive) for a $1 \mathrm{~h}$ session. Completion of the response criteria on the active lever resulted in the delivery of a food pellet, and activation of a cue light above the lever for the $20 \mathrm{~s}$ timeout duration. Responses on the inactive lever were recorded but had no scheduled consequences. Once stable responding was achieved (criteria $>30$ pellets per session across 3 daily consecutive sessions), the lever assignment was reversed in the subsequent session to examine cognitive flexibility on the reversal day. Specifically, the previous inactive lever became active, for which food pellets were delivered with the FR5TO20s schedule of reinforcement. In contrast, the previously active lever now became inactive, in which responses were recorded without scheduled consequence. Therefore, the mice were food trained for $\geq 5$ days to achieve stable responding, and then they were tested in the reversal session the following day. Thus, the baseline session represents the day immediately prior to reversal, whereas the reversal session represents the day of reversal. All behavioral responses were automatically recorded by MedAssociates software.

\section{Acoustic Startle Testing}

Startle and PPI testing were examined in startle chambers (SR-LAB, San Diego Instruments, United States), using an experimental design as previously described (van Enkhuizen et al., 2015; Figure 6A). Briefly, mice were placed into the startle chambers, which consisted of a Plexiglas cylinder, $5 \mathrm{~cm}$ in diameter, resting on a platform in a ventilated sound-attenuating box. Speakers mounted $33 \mathrm{~cm}$ above the cylinders produced the acoustic stimuli, and movements of the animal were transduced by piezoelectric accelerometers mounted under the cylinders and stored by the computer interface. The rodent's startle response data in the SR-Lab System is directly recorded from an accelerometer that produces as an analog output voltage signal in the millivolt $(\mathrm{mV})$ range. The rodent startle response includes movement of all 4 limbs crouching dynamically. Thus, the force of the movements generate voltage which the accelerometer records. Immediately prior to the PPI session, mice were permitted a $5 \mathrm{~min}$ acclimation period at $60 \mathrm{~dB}$ in the chamber. Thereafter, the PPI test consisted of a startle block comprising five $120 \mathrm{~dB}$ startle pulses, and the mean of these responses represents the baseline startle response value. Thereafter, five prepulse blocks were presented, which consisted of a $120 \mathrm{~dB}$ startle pulse preceded by either a $70 \mathrm{~dB}$ prepulse, $75 \mathrm{~dB}$ prepulse, $80 \mathrm{~dB}$ prepulse, or $85 \mathrm{~dB}$ prepulse. Each block presented the specific prepulses in a randomized manner. Prepulses were $20 \mathrm{~ms}$ in duration, the interstimulus intervals were $50 \mathrm{~ms}$, and the 
startle pulses were $40 \mathrm{~ms}$. In the programmed protocol, the intertrial interval had a random variable duration of 4-12 s. To calculate percent PPI, the following equation was used: Percent $\mathrm{PPI}=[(\mathrm{S}-\mathrm{P}) / \mathrm{S}] \times 100$, where $\mathrm{S}$ is the average baseline startle response per subject $(\mathrm{mV})$ and $\mathrm{P}$ is the average response following each prepulse and startle pairing $(\mathrm{mV})$. Thus, a lower value of percent PPI indicates a greater response in the presence of a prepulse, thereby demonstrating a decrease in sensorimotor gating; conversely, a higher percent PPI is indicative of more efficient sensorimotor gating.

\section{Statistical Analysis}

Data were analyzed using GraphPad Prism software (La Jolla, CA). For comparisons of two groups, data were analyzed using unpaired, two-tailed $t$-tests. If greater than two groups, data were analyzed using repeated measures (RM) two-way analysis of variance (ANOVA) with a Geisser-Greenhouse correction. The Geisser-Greenhouse correction was applied since we had no "a priori" assumptions for equal variability of differences within each group condition. This allows for matched values to be stacked into a subcolumn and individual variances to be computed for each comparison, in accordance with the repeated measures two-way ANOVA. Given variability in the baseline startle for PPI, we performed a ROUT outlier test, and the following were identified as outliers and removed from analysis: one male Lynx $1^{-/-}$, one female Lynx $1^{-/-}$and one female Lynx $1^{+/+}$. For multiple comparisons, the Sidak's post hoc test was employed, with statistical correction for multiple comparisons. The criterion for significance was set at $\alpha=0.05$.

\section{RESULTS}

\section{Lynx1 and Lynx2 mRNA Expression in the Brain}

Given that the PFC, cingulate cortex, and septum have been implicated in cognitive function, we examined lynx1 and lynx 2 mRNA expression across these brain regions. We found selective expression of lynx 2 in the more medial region of the PFC (Figure 1a), whereas the lateral PFC exhibited high lynx1 and lynx2 co-expression patterns (Figure 1b), with some cells exhibiting selective expression of either lynx1 or lynx2. A similar pattern was found in the cingulate cortex (Figure 1c), in which single- and co-expression patterns were evidenced. Interestingly in the septum, a distinct pattern emerged, in which lynx 2 appeared to be preferentially expressed in the lateral septum (Figure 1d), whereas the medial septum exhibited dense expression of lynx1 (Figure 1e); however, these expression patterns were not exclusive as few cells expressed lynx1 in the lateral septum and lynx2 in the medial septum. Next, we examined striatal regions and observed interesting differentiation depending on the subregion. Specifically, in the more anterior regions of the DST (Figure 2a), lynx1 was predominantly expressed, but in the posterior DST, higher levels of lynx2 were present (Figure 2c). Of further interest, when examined at lower magnification (Figure 2b), the localization of lynx2 in the dorsal striatum resembled striosome expression patterns (Brimblecombe and Cragg, 2017), although this localization will need to be confirmed in further studies. In the ventral striatum, we also found a higher density of expression for lynx2 in the NAcc (Figure 2d). In the dorsal hippocampus (Figure 3a), we found a high density of lynx1 and lynx2 with cell-layer selective expression patterns. Interestingly, when examined at higher magnification, distinct differences were found between CA3/CA2 and CA1, with preferential expression of lynx1 or lynx2, respectively (Figure $3 \mathbf{b}$ ). We also found both lynx1 and lynx2 expression in the central amygdala (Figure 3c), PPTg (Figure 3d), and PnC (Figure 3e), in which both co-localization and independent expression of either lynx1 or lynx2 were observed. Finally, we did not evidence any distinct differences between males and females in the overall expression patterns of lynx1 or lynx2; however, this will need to be examined more precisely with other techniques in future studies.

\section{Involvement of Lynx1 in Reversal Learning}

Since lynx1 was expressed in brain regions involved in behavioral learning (Kosaki and Watanabe, 2012; Kawai et al., 2015), we first examined the effects of Lynx1 gene knockout in a reversal learning operant food training task (Figure 4A). We found that both male lynx $1^{-/-}$and lynx $1^{+/+}$mice exhibited a significant decrease in the number of food pellets earned during the reversal session, as compared to the baseline session (Figure 4B) [RM two-way ANOVA: Genotype: $F_{(1,19)}=0.0067$, $p=0.9356$; Session: $F_{(1,19)}=14.46, p=0.0012$; Interaction: $F_{(1}$, $19)=0.0340, p=0.8557]$. The post hoc test comparing session revealed a significant decrease in the number of food rewards earned in both the male lynx $1^{-/-}(p=0.0430)$ and lynx $1^{+/+}$ ( $p=0.0187)$ mice, when comparing the baseline vs. reversal session. However, the decrease was not evident in the number of lever presses on the active lever, as both the male lynx $1^{-/-}$ and lynx $1^{+/+}$mice exhibited high levels of lever pressing in both sessions (Figure 4C) [RM two-way ANOVA: Genotype: $F_{(1}$, 19) $=0.0018, p=0.9669$; Session: $\left.F_{(1}, 19\right)=9.523, p=0.006$; Interaction: $\left.F_{(1}, 19\right)=0.0012, p=0.9727$; post hoc, lynx1 ${ }^{-/-}$ $(p=0.0947)$ and lynx $\left.1^{+/+}(p=0.0701)\right]$. For the females, the lynx $1^{-/-}$mice demonstrated no significant decrease in food pellets earned during reversal compared to baseline, whereas their lynx $1^{+/+}$littermates displayed a statistically significant decrease (Figure 4D) [RM two-way ANOVA: Genotype: $F_{(1}$, $20)=0.6945, p=0.4145$; Session: $F_{(1,20)}=11.61, p=0.0028$; Interaction: $\left.F_{(1,20)}=1.050, p=0.3177\right]$. Post hoc tests revealed significant differences for female lynx $1^{+/+}(p=0.0104)$, but not the lynx $1^{-/-}(p=0.2036)$, mice in the number of rewards earned on baseline vs. reversal day. When comparing active lever presses between sessions, similar effects were found with the female lynx $1^{-/-}$mice (Figure 4E) [RM two-way ANOVA: Genotype: $F_{(1,20)}=0.2623, p=0.6142$; Session: $F_{(1,20)}=7.248, p=0.014$; Interaction: $\left.\left.F_{(1}, 20\right)=0.6276, p=0.4375\right]$. The post hoc test revealed a significant decrease for female lynx $1^{+/+}(p=0.0453)$, but not lynx $1^{-/-}(p=0.3506)$, mice in the number of active 


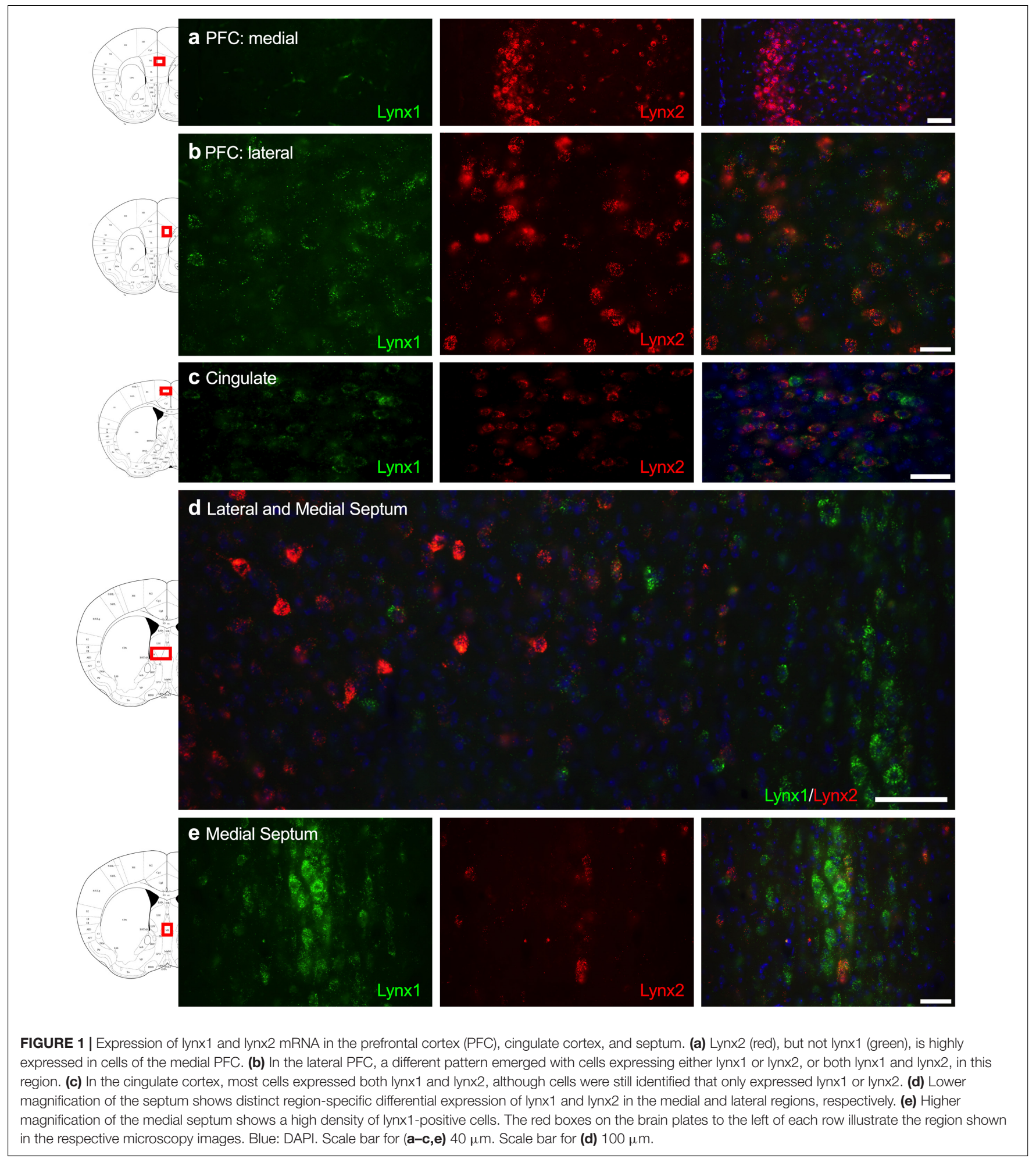

lever presses earned between the baseline and the reversal session. Therefore, the female lyn $\mathrm{x}^{-/-}$mice were highly efficient in the lever reversal task by adapting to the modified requirements. Together, these data indicate that removal of lynx1 does not induce deficits in cognitive flexibility.

\section{Involvement of Lynx2 in Reversal Learning}

We next examined lynx 2 mice in the reversal learning task. We found that male lynx $2^{+/+}$, but not lynx $2^{-/-}$, mice exhibited higher variability in the number of food pellets earned during 


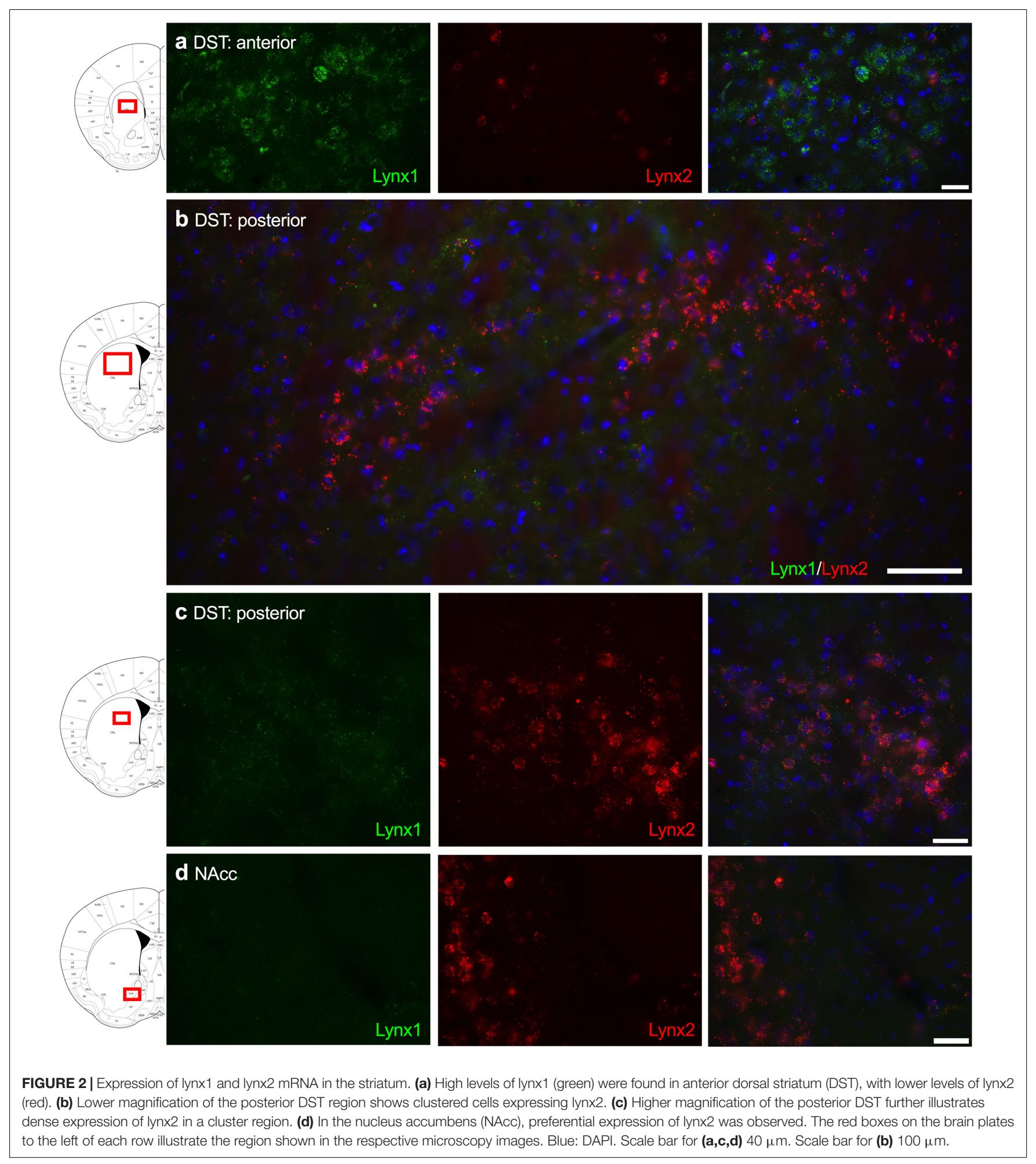

the reversal session, as compared to the baseline session (Figure 5A) [RM two-way ANOVA: Genotype: $F_{(1,34)}=0.1102$, $p=0.7420$; Session: $\left.F_{(1}, 34\right)=12.96, p=0.001$; Interaction: $F_{(1}$, $34)=1.065, p=0.3094]$. Post hoc tests revealed a significant decrease in rewards earned for male lynx $2^{+/+}(p=0.0038)$, but not the lynx $2^{-/-}(p=0.1647)$, mice on the baseline vs. reversal day. However, for active lever presses, neither male lynx $2^{-/-}$nor lynx $2^{+/+}$mice exhibited any differences between sessions with high rates of responding in both sessions (Figure 5B) [RM two-way ANOVA: Genotype: $F_{(1,34)}=0.4322$, 


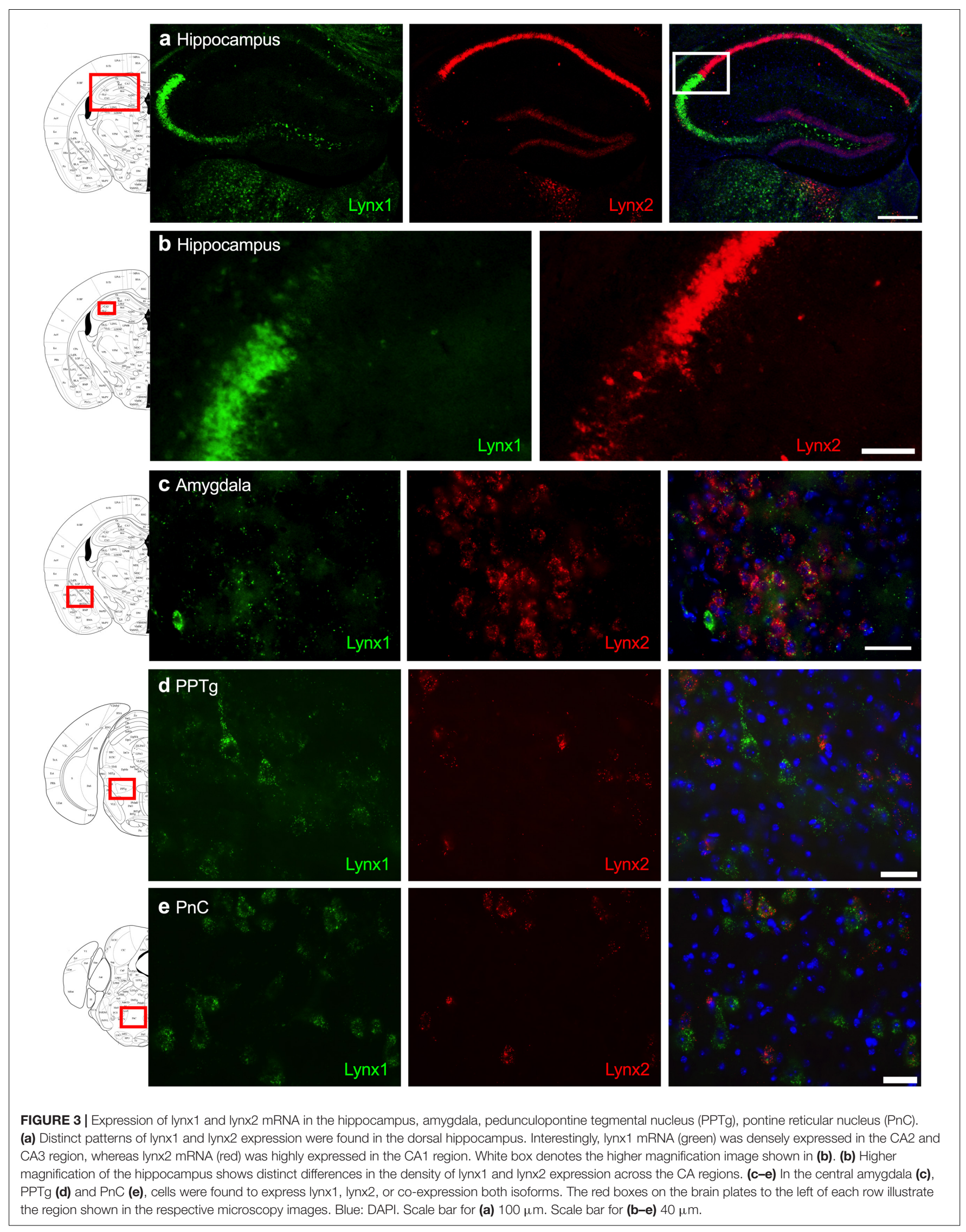




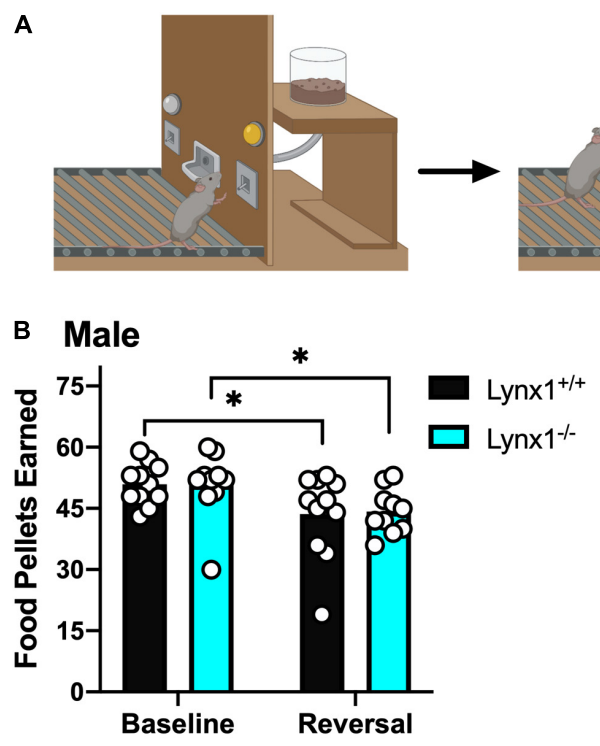

D Female

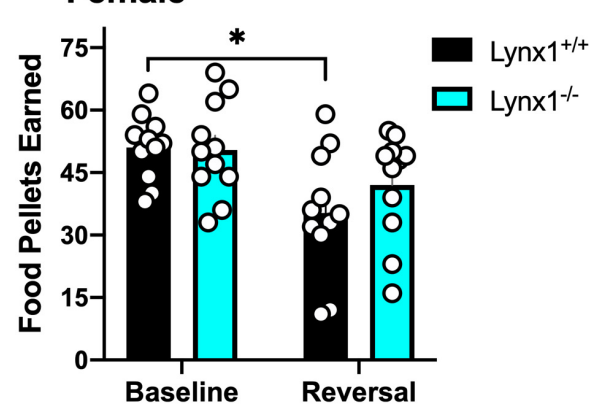

C

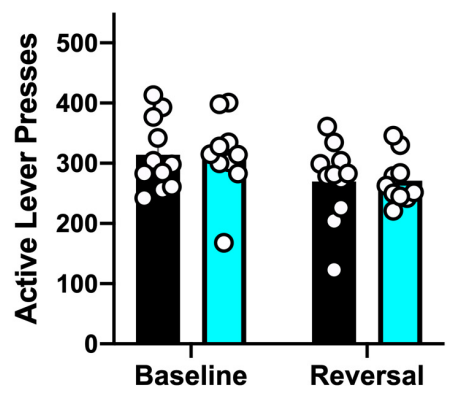

$\mathbf{E}$

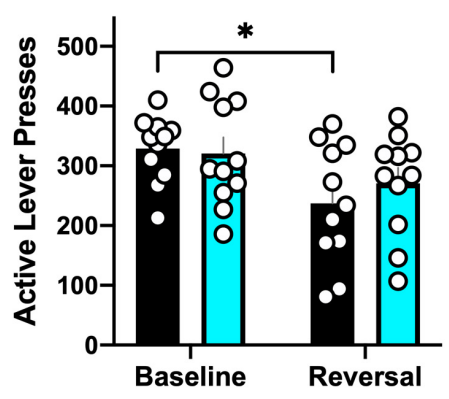

FIGURE 4 | Assessment of the role of lynx1 in cognitive flexibility. (A) Schematic demonstrating the reversal learning paradigm, in which the active lever is reversed after the mice have established a baseline level of responding for food reward. (B,C) Male lynx $1^{-/-}$and lynx $1^{+/+}$mice $(n=10-11 /$ group) displayed a significant decrease in the number of food pellets earned (B), but no difference in the number of active lever presses (C), comparing the baseline to the reversal session. (D,E) Female lyn $\times 1^{-/-}$and lynx $1^{+/+}$mice $\left(n=11 /\right.$ group) were also assessed in the reversal learning task. The female lynx $1^{-/-}$mice exhibited a similar level of lever pressing behavior across sessions, with no differences in the number of food pellets earned (D) or active lever presses (E) in the reversal session compared to their baseline level of responding. In contrast, the lynx $1^{+/+}$mice displayed a significant decrease in both of these measures for the reversal session. ${ }^{*} p<0.05$. Individual data points shown as white circles, and the bars represent mean \pm SEM. Image created with BioRender.com.

$p=0.5154$; Session: $F_{(1,34)}=6.878, p=0.0130 ;$ Interaction: $F_{(1}$, $34)=0.2682, p=0.6079$; post hoc, lynx $2^{-/-}(p=0.0741)$ and lynx $\left.2^{+/+}(p=0.2516)\right]$. For the females, both lynx2 genotypes demonstrated a significant decrease in food pellets earned during reversal compared to the baseline session (Figure 5C) [RM twoway ANOVA: Genotype: $\left.F_{(1}, 18\right)=0.7632, p=0.3938$; Session: $\left.F_{(1}, 18\right)=40.96, p<0.0001$; Interaction: $\left.F_{(1}, 18\right)=4.757$, $p=0.0427]$. Post hoc tests revealed significant differences for female lynx $2^{-/-}$mice $(p=0.0214)$ and lynx $2^{+/+}(p<0.0001)$ in the number of rewards earned on baseline vs. reversal day. Similarly, when comparing active lever presses between sessions, both female lynx $2^{-/-}$and lynx $2^{+/+}$displayed a significant decrease on the reversal session (Figure 5D) [RM two-way ANOVA: Genotype: $\left.F_{(1}, 18\right)=0.0132, p=0.9097$; Session: $F_{(1}$, 18) $=55.10, p<0.0001$; Interaction: $\left.F_{(1,18)}=5.934, p=0.0255\right]$. Post hoc tests revealed significant decrease for female lynx $2^{-1-}$ mice $(p=0.0069)$ and lynx $2^{+/+}(p<0.0001)$ in the number of active lever presses on the baseline vs. reversal session. Together, these findings indicate that lynx 2 does not significantly modulate processes underlying cognitive flexibility in the reversal task.

\section{Involvement of Lynx1 in Sensorimotor Gating With Prepulse Inhibition}

To examine the role of lynx1 in sensorimotor gating, we conducted the PPI assessment in the male and female lynx mice (Figure 6A). First, male lynx1 $1^{-/-}$mice exhibited no significant differences in their baseline startle response compared to lynx $1^{+/+}$littermates (Figure 6B) [two-tailed $t$-test: $t_{(19)}=2.013$, $p=0.0585]$. However, in the PPI assessment, significant differences between the responses of the lynx $1^{-/-}$and lynx $1^{+/+}$ mice were exhibited (Figure 6C) [RM two-way ANOVA: Genotype: $\left.F_{(1}, 19\right)=2.713, p=0.1160$; dB: $\left.F_{(2.053}, 39.00\right)=30.37$, $p<0.0001$; Interaction: $\left.F_{(3,57)}=9.268, p<0.0001\right]$. Specifically, 


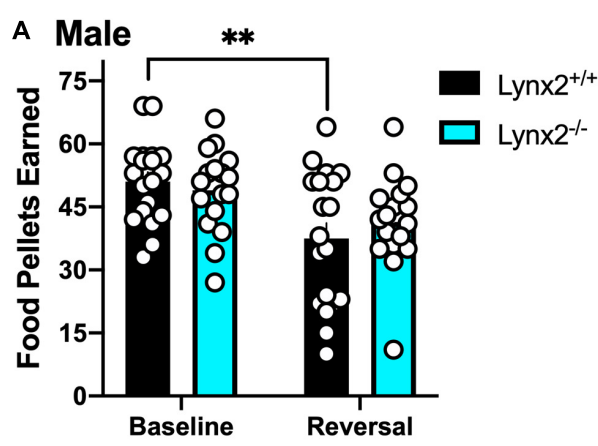

B
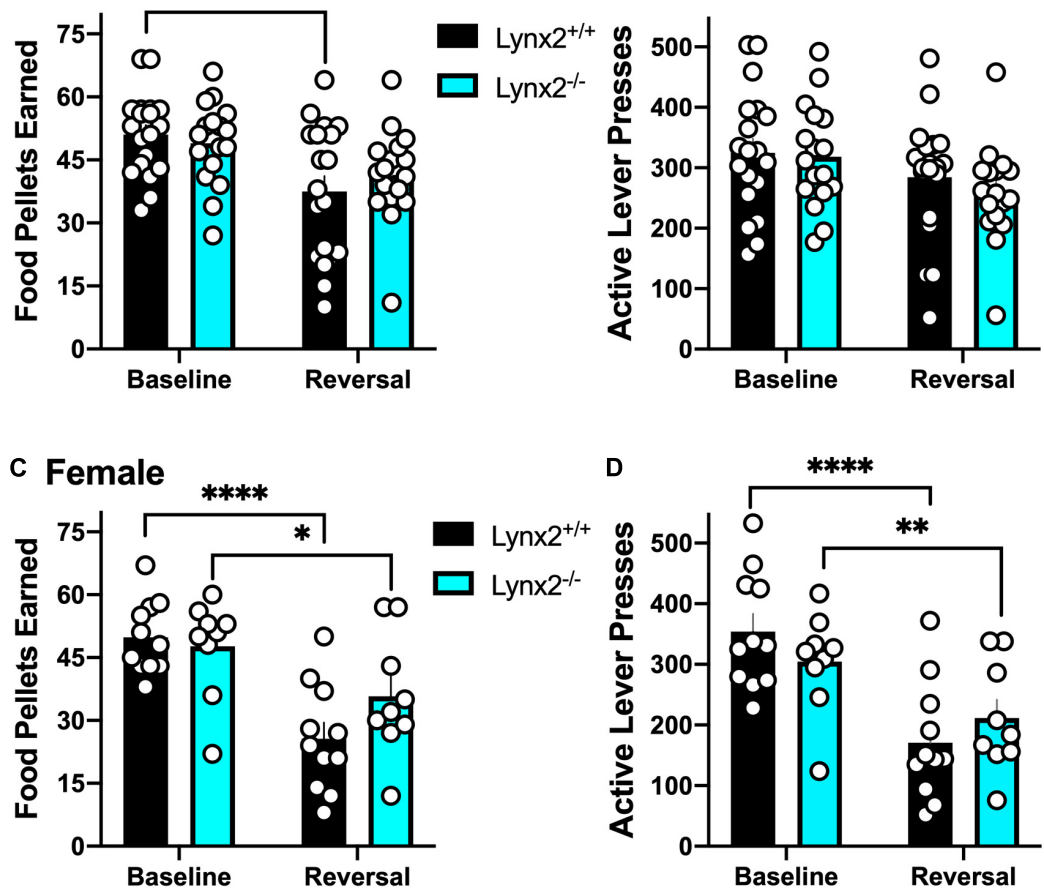

FIGURE 5 | Assessment of the role of lynx2 in cognitive flexibility. (A,B) Male lynx $2^{-/-}$and lynx2 $2^{+/}$mice $(n=17-19 /$ group) were examined in the reversal learning task. The lynx $2^{+/+}$mice displayed a significant decrease in the number of food pellets earned (A), but no difference in the number of active lever presses (B), comparing the reversal session to the baseline day. (C,D) Both lynx $2^{+/+}$and lynx $2^{-/-}$female mice $(n=9-11 /$ group) exhibited a significant decrease in number of food pellets earned (C) and active lever presses (D) in the reversal session compared to their baseline level of responding. ${ }^{*} p<0.05,{ }^{* *} p<0.01,{ }^{* * * *} p<0.0001$. Individual data points shown as white circles, and the bars represent mean \pm SEM.

the post hoc test revealed a significant decrease in percent PPI for the lynx1 $1^{-/-}$mice at the $80 \mathrm{~dB}(p=0.0023)$ and $85 \mathrm{~dB}$ $(p=0.0067)$, but not $70 \mathrm{~dB}$ or $75 \mathrm{~dB}$, compared to lynx $1^{+/+}$ levels. Female lynx $1^{-/-}$mice also exhibited no differences in baseline startle response compared to lynx $1^{+/+}$littermates (Figure 6D) [two-tailed $t$-test: $t_{(18)}=1.875, p=0.0771$ ], but differences were found in the percent PPI between genotypes (Figure 6E) [RM two-way ANOVA: Genotype: $F_{(1,18)}=0.3020$, $p=0.5894 ; \mathrm{dB}: F_{(2.589,46.61)}=27.17, p<0.0001$; Interaction: $F_{(3}$, $54)=3.215, p=0.0299]$. The post hoc test indicated a decrease in the percent PPI for the lynx1 $1^{-/}$mice at the $85 \mathrm{~dB}(p=0.0129)$, but not at the 70,75 , or $80 \mathrm{~dB}$ levels, compared to lynx $1^{+/+}$mice. Thus, removal of lynx1 led to a deficit in the percent PPI in both males and females, suggesting that the presence of lynx 1 is an important modulator of sensorimotor gating.

\section{Involvement of Lynx2 in Sensorimotor Gating With Prepulse Inhibition}

Next, we examined the involvement of the lynx2 isoform in sensorimotor gating to determine if these effects were specific to the interactions of lynx 1 with cholinergic signaling. We found that male lynx $2^{-/-}$mice exhibited a decreased baseline startle response (Figure 7A) [two-tailed $t$-test: $t_{(19)}=2.984, p=0.0076$ ], which was not found in females (Figure 7C) [two-tailed $t$-test: $\left.t_{(20)}=1.390, p=0.1799\right]$. However, in contrast to the findings with male lynx $1^{-/-}$mice, the male lynx $2^{-/-}$mice exhibited no statistical differences in their percent PPI responses (Figure 7B) [RM two-way ANOVA: Genotype: $\left.F_{(1}, 19\right)=0.5608, p=0.4631$; $\left.\mathrm{dB}: F_{(1.486}, 28.23\right)=52.19, p<0.0001$; Interaction: $F_{(3,57)}=6.166$, $p=0.0011]$. Although a main effect for $\mathrm{dB}$ and interaction effects were found, the post hoc did not reveal any differences between the genotypes at each $\mathrm{dB}$ level [post hoc, lynx $1^{-/-}$vs. lynx $2^{-/-}$ at $70 \mathrm{db}(p=0.9325), 75 \mathrm{db}(p=0.9732), 80 \mathrm{db}(p=0.6979)$, and $85 \mathrm{db}(p=0.1806)]$. Female lynx $2^{-/-}$mice also exhibited no differences in their PPI response compared to lynx $2^{+/+}$ littermates, although a main effect across $\mathrm{dB}$ was still present (Figure 7D) [RM two-way ANOVA: Genotype: $\left.F_{(1}, 20\right)=1.051$, $p=0.3176 ; \mathrm{dB}: F_{(2 \cdot 057,41 \cdot 15)}=9.534, p=0.0004$; Interaction: $\left.F_{(3,60)}=0.7208, p=0.5435\right]$. These data indicate that although lynx2 may mediate the initial startle response in males, it does not appear to be involved in the sensorimotor gating response.

\section{DISCUSSION}

In these studies, we characterized brain region expression patterns and examined the involvement of the endogenous allosteric modulators, lynx1 and lynx2, in reversal learning, startle reactivity and sensorimotor gating. Interestingly, we found that the absence of the lynx1 and lynx2 proteins did not induce deficits in either males or females with reversal learning. In 

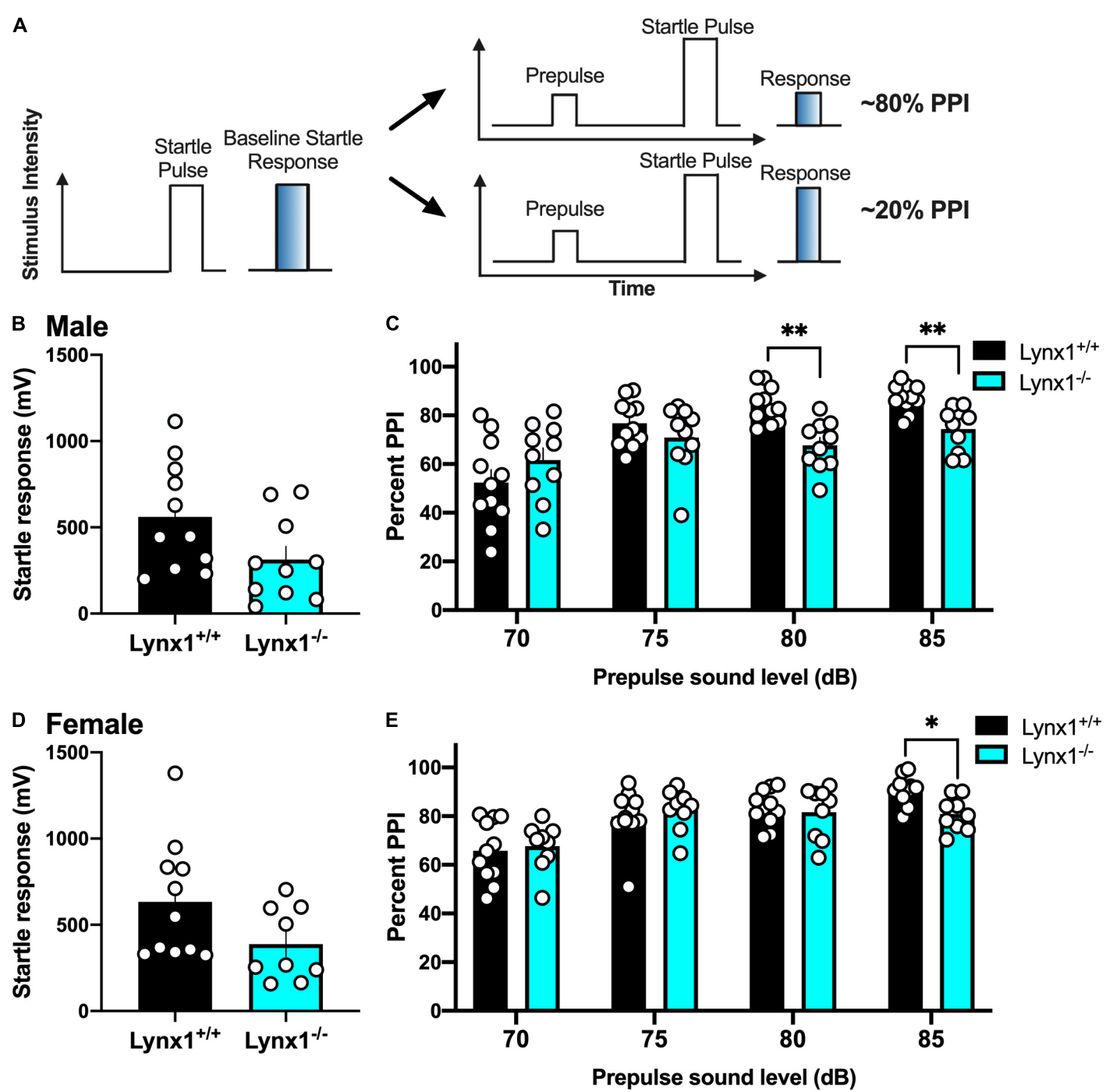

FIGURE 6 | Involvement of lynx1 in sensorimotor gating. (A) Schematic demonstrating the prepulse inhibition (PPI) procedure, in which a lower percent PPI is indicative of decreased sensorimotor gating following the prepulse paired with a startle pulse. Analysis of the baseline startle response (e.g., as represented by the left in $\mathbf{A}$ ) was first performed, followed by the prepulse and startle pulse paired sequence, with the prepulse of varying decibels (dB). (B) Male lynx $1^{+/+}$and lynx $1^{-/}$ mice ( $n=10-11 /$ group) exhibited no differences in their baseline startle response. (C) Following the presence of a prepulse, male lynx $1^{-/-}$mice exhibited a decrease in their percent PPI at the 80 and $85 \mathrm{~dB}$ prepulse compared to the lynx $1^{+/+}$mice. (D) Female lynx $1^{-/-}$and lynx $1^{+/+}$mice $(n=9-11 /$ group) exhibited no genotype differences in baseline startle response. (E) Following the presence of a prepulse, female lyn $\times 1^{-/-}$mice exhibited a significant decrease in percent PPI at the $85 \mathrm{~dB}$ prepulse compared to the lynx $1{ }^{+/+}$mice. ${ }^{*} p<0.05,{ }^{* *} p<0.01$. Individual data points shown as white circles, and the bars represent mean $\pm \mathrm{SEM}$. Image created with BioRender.com

contrast, a deficit in sensorimotor gating was found in both male and female lynx $1^{-/-}$mice, as they exhibited decreased PPI behavioral responses at moderate to higher prepulse decibels. Surprisingly, although lynx 2 is expressed in similar brain regions as lynx1, removal of the lynx 2 protein did not alter the PPI behavioral responses in either male or female mice, indicating differential functional roles of these isoforms.

\section{Lynx1, Lynx2, and Cognitive Flexibility}

In the present studies, we demonstrated that lynx1 and lynx2 are localized throughout many brain regions that have been implicated in cognitive flexibility, including the medial PFC, striatum, hippocampus, and cingulate cortex. Previous studies have not examined lynx 2 behaviorally in cognitive functions such as learning and memory, but it has been demonstrated that lynx2 can blunt nicotine-induced upregulation of the $\alpha 4 \beta 2$ containing nAChRs, which are involved in learning and memory function (Sadleir et al., 2013; Wu et al., 2015). Prior studies have found that lynx $1^{-/-}$mice exhibit an enhanced fear conditioned response compared to their wildtype littermates for cued, but not contextual, associated tasks (Miwa et al., 2006). In support of these findings, lynx $1^{-/-}$mice also exhibit normal contextual memory with passive avoidance conditioning and in the Morris Water maze (Miwa et al., 2006). Given these 

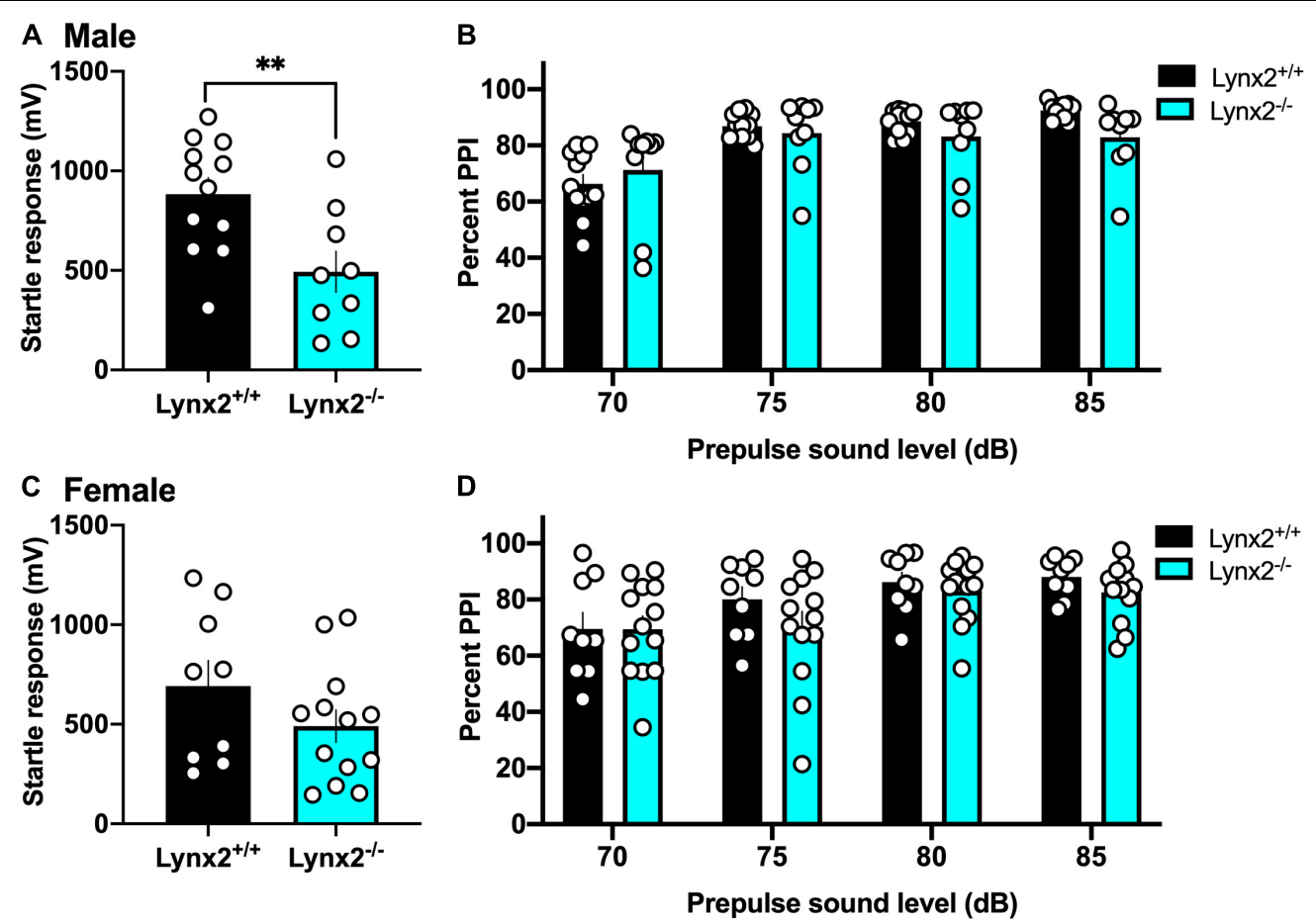

FIGURE 7 | Lack of association between lynx2 and sensorimotor gating. (A) For the baseline startle response, male lynx2 $2^{-/-}$and lynx2 ${ }^{+/+}$mice $(n=9-12 / g r o u p)$ were examine, and the lynx $2^{-/-}$exhibited a decrease in their startle reactivity compared to lynx $2^{+/+}$littermates. (B) Following the presence of a prepulse, male lynx $2^{-/-}$mice exhibited no differences in their percent PPI compared to the lynx2 $2^{+/+}$mice. (C,D) Female lynx $2^{-/-}$and lynx $2^{+/+}$mice $(n=9-13 / g r o u p)$ exhibited no differences in the baseline startle response (C) or percent PPI (D). ${ }^{* *} p<0.01$. Individual data points shown as white circles, and the bars represent mean \pm SEM.

data, we hypothesized that lynx $1^{-/-}$mice would exhibit an altered response in the lever reversal task, which involves cueassociated learning with the pairing of a cue light and food reward upon completion of response criteria on the active lever. However, while the female lynx $1^{-/-}$mice appeared to switch their responses more efficiently to receive food rewards on the previously inactive lever, there was not a significant genotype effect. Since this task involves a visual light cue above the active lever, it's important to note that lynx1 has been implicated in regulating spine dynamics in the visual cortex (Miwa et al., 2006; Morishita et al., 2010; Bukhari et al., 2015; Sajo et al., 2016). However, these effects were found during critical periods for visual plasticity, and adult lynx $1^{-/-}$mice demonstrate normal dendritic complexity and spine density in primary visual cortical neurons (Sajo et al., 2016), which supports the current results as no deficits were evidenced. Furthermore, the presence of lynx1 has been suggested to serve as a neuroprotective factor in aged animals, such that older lynx $1^{-/-}$mice develop loss of nerve fibers in the dorsal striatum, a brain region implicated in habitual behavior and reversal learning (Kobayashi et al., 2014; Bonnavion et al., 2019). However, the neuroprotective role of lynx1 appears to emerge in mice after 13 months of age (Kobayashi et al., 2014), which exceeds the age of the mice in the current study. Thus, it would be of interest in further studies to examine whether deficits in the reversal task would emerge in older lynx $1^{-/-}$animals and whether the administration of nicotine would lead to differential interactive effects between the lynx isoforms and receptor signaling in cognitive flexibility measures.

\section{Lynx1, Lynx2, and Sensorimotor Gating}

Lynx1 and lynx2 were found to be expressed throughout brain regions, with distinct single- and co-expression patterns. The regional hippocampal expression evidenced is consistent with prior literature, in which lynx1 and lynx2 are differentially expressed in the CA1, CA2, and CA3 regions, as determined previously with in situ hybridization (Miwa et al., 1999; Dessaud et al., 2006; Tekinay et al., 2009). The septum, PPTg, PnC, NAcc, hippocampus and amygdala have been shown to regulate PPIrelevant sensorimotor and cognitive processing across species (Swerdlow and Geyer, 1993; Swerdlow et al., 1995, 2007; Wan and Swerdlow, 1997; Bakshi and Geyer, 1998; Schell et al., 2000; Baldan Ramsey et al., 2011; Takeuchi et al., 2011; Kucinski et al., 2012; Azzopardi et al., 2018; Kiziltan et al., 2018; Jin et al., 2019; Sullivan et al., 2019; Cano et al., 2021), thereby supporting the notion that presynaptic or postsynaptic cholinergic modulation via the lynx proteins could underlie such cognitive processing. Indeed, we found that both male and female lynx $1^{-/}$mice exhibited decreased PPI behavioral responses following moderate prepulse decibels, an effect which was not found in the lynx2 mice. Importantly, lynx $1^{-/-}$ mice have been shown to exhibit normal auditory thresholds (Takesian et al., 2018), indicating that the current findings cannot be attributed to deficits in auditory processing. Of 
further interest, removal of lynx1 results in the differential expression of genes potentially associated with Schizophrenia (Smith et al., 2018), suggesting that lynx1 may function upstream to regulate the expression of other signaling molecules involved in psychiatric symptomology. It is also possible that differences in anxiety-related behaviors may confer altered responses in the PPI assessment. However, lynx $1^{-/-}$mice do not exhibit differences in anxiety-associated behaviors, as previously assessed in the elevated plus maze and open field test (Miwa et al., 2006). Interestingly, lynx $2^{-/-}$does result in increased anxietyassociated behaviors (Tekinay et al., 2009), although we found no differences in sensorimotor gating with PPI in these mice. Thus, the anxiety-associated phenotype did not contribute to an altered sensorimotor gating effect. However, we did observe a lower baseline startle response with the initial series of auditory pulses in male lynx $2^{-/-}$mice. These results are intriguing given that (1) differences were not found in the females and (2) deficits in the baseline startle response did not correlate with the subsequent differences between groups in percent PPI. Thus, each of these measures supports the relevance of the findings for lynx1 in mediating behavioral motor responses to sensory stimuli.

\section{Importance of Examining Both Males and Females}

Our studies included both males and females, unlike other prior reports in the field that have focused on males (Miwa et al., 2006). Our goal was to potentially reveal behavioral differences occurring within each sex in the absence of lynx 1 or lynx2. Of note, estrogen has been found to act as a positive allosteric modulator for nAChRs by increasing the open state probability of the channel with ligand binding (Curtis et al., 2002). Further, estrogen receptors localized on cholinergic terminals in the hippocampus have been shown to increase acetylcholine release (Packard et al., 1996; Towart et al., 2003), and cholinergic modulation of inhibitory neurons in the hippocampus can be modified by estrogen's effects on synaptogenesis (Murphy et al., 1998; Rudick et al., 2003). In addition to these activational effects of estrogen, organizational effects during development can result in functional differences. For instance, sex differences have been documented in the membrane localization of estrogen receptors and subsequent excitation of hippocampal circuits (Oberlander and Woolley, 2016). Since testosterone can be converted locally into estrogen in the male brain (Schulster et al., 2016), it is possible that this hormone exerts differential actions on cholinergic signaling based on the level of expression and localization of estrogen receptors within brain regions, such as the hippocampus. Taken together, these prior studies demonstrate both organizational and activational effects of estrogen and highlight the notion that estrogen may interact with lynx at different developmental stages to modulate function of the nAChRs. Thus, given that males and females fluctuate in their hormonal levels across varying daily cycles, a future study controlling for the relative levels of testosterone and estrogen will be essential to more clearly define such an interaction.

\section{CONCLUSION}

These studies demonstrate a role for lynx1 in various aspects of cognitive processing with sex-specific effects. It will be important in future studies to ascertain the cell-type specific patterns of expression for the lynx proteins within different brain circuits and to precisely assess the potential competition of positive and negative allosteric modulators of the nAChRs at the synaptic level between sexes. In addition, given the use of nicotine with tobacco cigarettes and e-cigarettes among the population, it should be noted that nicotine's actions on the nAChR may also be modulated by the presence of the lynx proteins, such as that previously demonstrated with nicotine-mediated nociception, dexterity and grip strength, and glutamate signaling in animal models (Tekinay et al., 2009; Miwa and Walz, 2012; Nissen et al., 2018). Therefore, it will be of interest in future studies to determine if the administration of nicotine or other $\mathrm{nAChR}$ ligands interacts with lynx processing to modulate cognitive flexibility or the sensorimotor gating response. Furthermore, it will be interesting to examine lynx1 and lynx2 knockdown or overexpression in specific brain regions on reversal learning and PPI, either in the presence or absence of nAChR ligands. Finally, these findings also highlight a potential role for therapeutic targeting of lynx1 and/or its allosteric binding site on nAChRs to promote more efficient sensorimotor processing by increasing the activity of lynx1 signaling mechanisms.

\section{DATA AVAILABILITY STATEMENT}

The original contributions presented in the study are included in the article/supplementary material, further inquiries can be directed to the corresponding author/s.

\section{ETHICS STATEMENT}

The animal study was reviewed and approved by the University of California Irvine IACUC.

\section{AUTHOR CONTRIBUTIONS}

YS, VL, and CF were responsible for the study concept and design. YS, EC, VL, MB, JF, and Y-CC contributed to the acquisition of animal data. YS, EC, MB, and CF conducted the data analysis and interpreted the findings. JM provided the lynx1 and lynx2 knockout breeders, genotyping protocol and conceptual guidance. All authors contributed to drafting the manuscript, providing critical revision of the manuscript for important intellectual content, and then approved final version for publication.

\section{FUNDING}

This work was supported by grants from the TobaccoRelated Disease Research Program (TRDRP T30IP0931 to CF; T30FT0967 to VL), NIH National Institute on Drug Abuse (DP1 DA039658 to CF; DA043567 to JM; and F31 DA050436 to YS). 


\section{REFERENCES}

Anderson, K. R., Hoffman, K. M., and Miwa, J. M. (2020). Modulation of cholinergic activity through lynx prototoxins: implications for cognition and anxiety regulation. Neuropharmacology 174:108071. doi: 10.1016/j. neuropharm.2020.108071

Artoni, P., Piffer, A., Vinci, V., Leblanc, J., Nelson, C. A., Hensch, T. K., et al. (2020). Deep learning of spontaneous arousal fluctuations detects early cholinergic defects across neurodevelopmental mouse models and patients. Proc. Natl. Acad. Sci. U. S. A. 117, 23298-23303. doi: 10.1073/pnas. 1820847116

Azzopardi, E., Louttit, A. G., Deoliveira, C., Laviolette, S. R., and Schmid, S. (2018). The Role of Cholinergic Midbrain Neurons in Startle and Prepulse Inhibition. J. Neurosci. 38, 8798-8808. doi: 10.1523/jneurosci.0984-18.2018

Bakshi, V. P., and Geyer, M. A. (1998). Multiple limbic regions mediate the disruption of prepulse inhibition produced in rats by the noncompetitive NMDA antagonist dizocilpine. J. Neurosci. 18, 8394-8401. doi: 10.1523/ jneurosci.18-20-08394.1998

Baldan Ramsey, L. C., Xu, M., Wood, N., and Pittenger, C. (2011). Lesions of the dorsomedial striatum disrupt prepulse inhibition. Neuroscience 180, 222-228. doi: 10.1016/j.neuroscience.2011.01.041

Bechard, A. R., Lacrosse, A., Namba, M. D., Jackson, B., and Knackstedt, L. A. (2018). Impairments in reversal learning following short access to cocaine self-administration. Drug Alcohol Depend. 192, 239-244.

Bonnavion, P., Fernandez, E. P., Varin, C., and De Kerchove D'exaerde, A. (2019). It takes two to tango: dorsal direct and indirect pathways orchestration of motor learning and behavioral flexibility. Neurochem. Int. 124, 200-214.

Brimblecombe, K. R., and Cragg, S. J. (2017). The Striosome and Matrix Compartments of the Striatum: a Path through the Labyrinth from Neurochemistry toward Function. ACS Chem. Neurosci. 8, 235-242. doi: 10. 1021/acschemneuro.6b00333

Bukhari, N., Burman, P. N., Hussein, A., Demars, M. P., Sadahiro, M., Brady, D. M., et al. (2015). Unmasking Proteolytic Activity for Adult Visual Cortex Plasticity by the Removal of Lynx1. J. Neurosci. 35, 12693-12702. doi: 10.1523/jneurosci. 4315- 14.2015

Bychkov, M., Shenkarev, Z., Shulepko, M., Shlepova, O., Kirpichnikov, M., and Lyukmanova, E. (2019). Water-soluble variant of human Lynx1 induces cell cycle arrest and apoptosis in lung cancer cells via modulation of alpha7 nicotinic acetylcholine receptors. PLoS One 14:e0217339. doi: 10.1371/journal. pone. 0217339

Cano, J. C., Huang, W., and Fenelon, K. (2021). The amygdala modulates prepulse inhibition of the auditory startle reflex through excitatory inputs to the caudal pontine reticular nucleus. BMC Biol. 19:116. doi: 10.1186/s12915-021-01050-z

Castane, A., Theobald, D. E., and Robbins, T. W. (2010). Selective lesions of the dorsomedial striatum impair serial spatial reversal learning in rats. Behav. Brain Res. 210, 74-83. doi: 10.1016/j.bbr.2010.02.017

Chen, E., Lallai, V., Sherafat, Y., Grimes, N. P., Pushkin, A. N., Fowler, J. P., et al. (2018). Altered Baseline and Nicotine-Mediated Behavioral and Cholinergic Profiles in ChAT-Cre Mouse Lines. J. Neurosci. 38, 2177-2188. doi: 10.1523/ jneurosci.1433-17.2018

Chen, Y. C., Fowler, J. P., Wang, J., Watson, C. J. W., Sherafat, Y., Staben, A., et al. (2020). The Novel CYP2A6 Inhibitor, DLCI-1, Decreases Nicotine SelfAdministration in Mice. J. Pharmacol. Exp. Ther. 372, 21-29. doi: 10.1124/jpet. 119.260653

Court, J., Spurden, D., Lloyd, S., Mckeith, I., Ballard, C., Cairns, N., et al. (1999). Neuronal nicotinic receptors in dementia with Lewy bodies and schizophrenia: alpha-bungarotoxin and nicotine binding in the thalamus. J. Neurochem. 73, 1590-1597. doi: 10.1046/j.1471-4159.1999.0731590.x

Curtis, L., Buisson, B., Bertrand, S., and Bertrand, D. (2002). Potentiation of human alpha4beta2 neuronal nicotinic acetylcholine receptor by estradiol. Mol. Pharmacol. 61, 127-135. doi: 10.1124/mol.61.1.127

Dalton, G. L., Wang, N. Y., Phillips, A. G., and Floresco, S. B. (2016). Multifaceted Contributions by Different Regions of the Orbitofrontal and Medial Prefrontal Cortex to Probabilistic Reversal Learning. J. Neurosci. 36, 1996-2006. doi: 10.1523/jneurosci.3366-15.2016

Dargis, M., Wolf, R. C., and Koenigs, M. (2017). Reversal learning deficits in criminal offenders: effects of psychopathy, substance use, and childhood maltreatment history. J. Psychopathol. Behav. Assess. 39, 189-197. doi: 10.1007/ s10862-016-9574-6 de la Salle, S., Smith, D., Choueiry, J., Impey, D., Philippe, T., Dort, H., et al. (2013). Effects of COMT genotype on sensory gating and its modulation by nicotine: differences in low and high P50 suppressors. Neuroscience 241, 147-156. doi: 10.1016/j.neuroscience.2013.03.029

Dessaud, E., Salaun, D., Gayet, O., Chabbert, M., and Delapeyriere, O. (2006). Identification of lynx2, a novel member of the ly-6/neurotoxin superfamily, expressed in neuronal subpopulations during mouse development. Mol. Cell. Neurosci. 31, 232-242. doi: 10.1016/j.mcn.2005.09.010

Disney, A. A., Aoki, C., and Hawken, M. J. (2007). Gain modulation by nicotine in macaque v1. Neuron 56, 701-713. doi: 10.1016/j.neuron.2007.09.034

Dong, C., Kern, N. R., Anderson, K. R., Zhang, X. F., Miwa, J. M., and Im, W. (2020). Dynamics and Interactions of GPI-Linked lynx1 Protein with/without Nicotinic Acetylcholine Receptor in Membrane Bilayers. J. Phys. Chem. B 124, 4017-4025. doi: 10.1021/acs.jpcb.0c00159

Fellows, L. K., and Farah, M. J. (2003). Ventromedial frontal cortex mediates affective shifting in humans: evidence from a reversal learning paradigm. Brain 126, 1830-1837. doi: 10.1093/brain/awg180

Freitas, K., Carroll, F. I., and Damaj, M. I. (2013). The antinociceptive effects of nicotinic receptors alpha7-positive allosteric modulators in murine acute and tonic pain models. J. Pharmacol. Exp. Ther. 344, 264-275.

Fuentealba, J., Olivares, R., Ales, E., Tapia, L., Rojo, J., Arroyo, G., et al. (2004). A choline-evoked [Ca2+]c signal causes catecholamine release and hyperpolarization of chromaffin cells. FASEB J. 18, 1468-1470. doi: 10.1096/ fj.04-1828fje

George, A. A., Bloy, A., Miwa, J. M., Lindstrom, J. M., Lukas, R. J., and Whiteaker, P. (2017). Isoform-specific mechanisms of alpha3beta 4 -nicotinic acetylcholine receptor modulation by the prototoxin lynx1. FASEB J. 31, 1398-1420. doi: 10.1096/fj.201600733r

Golubic, S. J., Jurasic, M. J., Susac, A., Huonker, R., Gotz, T., and Haueisen, J. (2019). Attention modulates topology and dynamics of auditory sensory gating. Hum. Brain Mapp. 40, 2981-2994.

Holford, M., Auer, S., Laqua, M., and Ibanez-Tallon, I. (2009). Manipulating neuronal circuits with endogenous and recombinant cell-surface tethered modulators. Front. Mol. Neurosci. 2:21. doi: 10.3389/neuro.02.021.2009

Ibanez-Tallon, I., Miwa, J. M., Wang, H. L., Adams, N. C., Crabtree, G. W., Sine, S. M., et al. (2002). Novel modulation of neuronal nicotinic acetylcholine receptors by association with the endogenous prototoxin lynx1. Neuron 33, 893-903.

Izquierdo, A., Brigman, J. L., Radke, A. K., Rudebeck, P. H., and Holmes, A. (2017). The neural basis of reversal learning: an updated perspective. Neuroscience 345, 12-26. doi: 10.1016/j.neuroscience.2016.03.021

Jin, J., Cheng, J., Lee, K. W., Amreen, B., Mccabe, K. A., Pitcher, C., et al. (2019). Cholinergic Neurons of the Medial Septum Are Crucial for Sensorimotor Gating. J. Neurosci. 39, 5234-5242. doi: 10.1523/jneurosci.0950-18.2019

Kawai, T., Yamada, H., Sato, N., Takada, M., and Matsumoto, M. (2015). Roles of the Lateral Habenula and Anterior Cingulate Cortex in Negative Outcome Monitoring and Behavioral Adjustment in Nonhuman Primates. Neuron 88, 792-804. doi: 10.1016/j.neuron.2015.09.030

Kiziltan, M. E., Alpaslan, B. G., Ozkara, C., Uzan, M., and Gunduz, A. (2018). Role of mesial temporal lobe structures in sensory processing in humans: a prepulse modulation study in temporal lobe epilepsy. Exp. Brain Res. 236, 3297-3305. doi: 10.1007/s00221-018-5380-6

Kleinmans, M., and Bilkey, D. K. (2018). Reversal learning impairments in the maternal immune activation rat model of schizophrenia. Behav. Neurosci. 132, 520-525. doi: 10.1037/bne0000275

Kobayashi, A., Parker, R. L., Wright, A. P., Brahem, H., Ku, P., Oliver, K. M., et al. (2014). Lynx1 supports neuronal health in the mouse dorsal striatum during aging: an ultrastructural investigation. J. Mol. Neurosci. 53, 525-536. doi: 10.1007/s12031-014-0352-1

Kosaki, Y., and Watanabe, S. (2012). Dissociable roles of the medial prefrontal cortex, the anterior cingulate cortex, and the hippocampus in behavioural flexibility revealed by serial reversal of three-choice discrimination in rats. Behav. Brain Res. 227, 81-90.

Kucinski, A., Syposs, C., Wersinger, S., Bencherif, M., Stachowiak, M. K., and Stachowiak, E. K. (2012). alpha7 neuronal nicotinic receptor agonist (TC-7020) reverses increased striatal dopamine release during acoustic PPI testing in a transgenic mouse model of schizophrenia. Schizophr. Res. 136, 82-87. 
Le Novere, N., Corringer, P. J., and Changeux, J. P. (2002). The diversity of subunit composition in nAChRs: evolutionary origins, physiologic and pharmacologic consequences. J. Neurobiol. 53, 447-456.

Levy-Gigi, E., Haim-Nachum, S., Hall, J. M., Crouse, J. J., Winwood-Smith, R., Lewis, S. J. G., et al. (2019). The interactive effect of valence and context on reversal learning in individuals with Parkinson's disease. Neurosci. Lett. 692, 216-224.

Lipsius, S. L. (1982). Acetylcholine and potassium-42 movements in right atrial muscle of the guinea pig. J. Auton. Nerv. Syst. 5, 279-289. doi: 10.1016/0165$1838(82) 90071-6$

Miwa, J. M. (2020). Lynx1 prototoxins: critical accessory proteins of neuronal nicotinic acetylcholine receptors. Curr. Opin. Pharmacol. 56, 46-51. doi: 10. 1016/j.coph.2020.09.016

Miwa, J. M., Anderson, K. R., and Hoffman, K. M. (2019). Lynx Prototoxins: roles of Endogenous Mammalian Neurotoxin-Like Proteins in Modulating Nicotinic Acetylcholine Receptor Function to Influence Complex Biological Processes. Front. Pharmacol. 10:343. doi: 10.3389/fphar.2019.00343

Miwa, J. M., Freedman, R., and Lester, H. A. (2011). Neural systems governed by nicotinic acetylcholine receptors: emerging hypotheses. Neuron 70, 20-33. doi: 10.1016/j.neuron.2011.03.014

Miwa, J. M., Ibanez-Tallon, I., Crabtree, G. W., Sanchez, R., Sali, A., Role, L. W., et al. (1999). Lynxl, an endogenous toxin-like modulator of nicotinic acetylcholine receptors in the mammalian CNS. Neuron 23, 105-114. doi: 10.1016/S0896-6273(00)80757-6

Miwa, J. M., Lester, H. A., and Walz, A. (2012). Optimizing cholinergic tone through lynx modulators of nicotinic receptors: implications for plasticity and nicotine addiction. Physiology 27, 187-199. doi: 10.1152/physiol.00002.2012

Miwa, J. M., Stevens, T. R., King, S. L., Caldarone, B. J., Ibanez-Tallon, I., Xiao, C., et al. (2006). The prototoxin lynx1 acts on nicotinic acetylcholine receptors to balance neuronal activity and survival in vivo. Neuron 51, 587-600. doi: 10.1016/j.neuron.2006.07.025

Miwa, J. M., and Walz, A. (2012). Enhancement in motor learning through genetic manipulation of the Lynx1 gene. PLoS One 7:e43302. doi: 10.1371/journal.pone. 0043302

Morishita, H., Miwa, J. M., Heintz, N., and Hensch, T. K. (2010). Lynx1, a cholinergic brake, limits plasticity in adult visual cortex. Science 330, 1238-1240. doi: $10.1126 /$ science. 1195320

Murphy, D. D., Cole, N. B., Greenberger, V., and Segal, M. (1998). Estradiol increases dendritic spine density by reducing GABA neurotransmission in hippocampal neurons. J. Neurosci. 18, 2550-2559. doi: 10.1523/JNEUROSCI. 18-07-02550.1998

Nichols, W. A., Henderson, B. J., Yu, C., Parker, R. L., Richards, C. I., Lester, H. A., et al. (2014). Lynx1 shifts alpha4beta2 nicotinic receptor subunit stoichiometry by affecting assembly in the endoplasmic reticulum. J. Biol. Chem. 289, 3142331432. doi: 10.1074/jbc.M114.573667

Nissen, N. I., Anderson, K. R., Wang, H., Lee, H. S., Garrison, C., Eichelberger, S. A., et al. (2018). Augmenting the antinociceptive effects of nicotinic acetylcholine receptor activity through lynx1 modulation. PLoS One 13:e199643. doi: 10. 1371/journal.pone.0199643

Oberlander, J. G., and Woolley, C. S. (2016). 17beta-Estradiol Acutely Potentiates Glutamatergic Synaptic Transmission in the Hippocampus through Distinct Mechanisms in Males and Females. J. Neurosci. 36, 2677-2690. doi: 10.1523/ JNEUROSCI.4437-15.2016

Packard, M. G., Kohlmaier, J. R., and Alexander, G. M. (1996). Posttraining intrahippocampal estradiol injections enhance spatial memory in male rats: interaction with cholinergic systems. Behav. Neurosci. 110, 626-632. doi: 10. 1037/0735-7044.110.3.626

Pushkin, A. N., Eugene, A. J., Lallai, V., Torres-Mendoza, A., Fowler, J. P., Chen, E., et al. (2019). Cannabinoid and nicotine exposure during adolescence induces sex-specific effects on anxiety- and reward-related behaviors during adulthood. PLoS One 14:e0211346. doi: 10.1371/journal.pone.0211346

Rudick, C. N., Gibbs, R. B., and Woolley, C. S. (2003). A role for the basal forebrain cholinergic system in estrogen-induced disinhibition of hippocampal pyramidal cells. J. Neurosci. 23, 4479-4490. doi: 10.1523/JNEUROSCI.23-1104479.2003

Sadleir, K. R., Bennett, D. A., Schneider, J. A., and Vassar, R. (2013). Elevated Abeta 42 in aged, non-demented individuals with cerebral atherosclerosis. Curr. Alzheimer Res. 10, 785-789. doi: 10.2174/15672050113109990152
Sajo, M., Ellis-Davies, G., and Morishita, H. (2016). Lynx1 Limits Dendritic Spine Turnover in the Adult Visual Cortex. J. Neurosci. 36, 9472-9478. doi: 10.1523/ JNEUROSCI.0580-16.2016

Schell, A. M., Wynn, J. K., Dawson, M. E., Sinaii, N., and Niebala, C. B. (2000). Automatic and controlled attentional processes in startle eyeblink modification: effects of habituation of the prepulse. Psychophysiology 37, 409-417. doi: 10. 1111/1469-8986.3740409

Schoenbaum, G., Chiba, A. A., and Gallagher, M. (2000). Changes in functional connectivity in orbitofrontal cortex and basolateral amygdala during learning and reversal training. J. Neurosci. 20, 5179-5189. doi: 10.1523/JNEUROSCI. 20-13-05179.2000

Schulster, M., Bernie, A. M., and Ramasamy, R. (2016). The role of estradiol in male reproductive function. Asian J. Androl. 18, 435-440. doi: 10.4103/1008-682X. 173932

Sherafat, Y., Bautista, M., and Fowler, C. D. (2021). Multidimensional Intersection of Nicotine, Gene Expression, and Behavior. Front. Behav. Neurosci. 15:649129. doi: 10.3389/fnbeh.2021.649129

Sherafat, Y., Bautista, M., Fowler, J. P., Chen, E., Ahmed, A., and Fowler, C. D. (2020). The Interpeduncular-Ventral Hippocampus Pathway Mediates Active Stress Coping and Natural Reward. eNeuro 7:2020. doi: 10.1523/ENEURO. 0191-20.2020

Smith, M. R., Glicksberg, B. S., Li, L., Chen, R., Morishita, H., and Dudley, J. T. (2018). Loss-of-function of neuroplasticity-related genes confers risk for human neurodevelopmental disorders. Pac. Symp. Biocomput. 23, 68-79. doi: 10.1142/ 9789813235533_0007

Solari, N., and Hangya, B. (2018). Cholinergic modulation of spatial learning, memory and navigation. Eur. J. Neurosci. 48, 2199-2230. doi: 10.1111/ejn. 14089

Stolyarova, A., Rakhshan, M., Hart, E. E., O’dell, T. J., Peters, M. A. K., Lau, H., et al. (2019). Contributions of anterior cingulate cortex and basolateral amygdala to decision confidence and learning under uncertainty. Nat. Commun. 10:4704. doi: 10.1038/s41467-019-12725-1

Sullivan, J. M. III, Grant, C. A., Reker, A. N., Nahar, L., Goeders, N. E., and Nam, H. W. (2019). Neurogranin regulates sensorimotor gating through corticostriatal circuitry. Neuropharmacology 150, 91-99. doi: 10.1016/j.neuropharm. 2019.03.021

Swerdlow, N. R., Braff, D. L., and Geyer, M. A. (1999). Cross-species studies of sensorimotor gating of the startle reflex. Ann. N. Y. Acad. Sci. 877, 202-216. doi: 10.1111/j.1749-6632.1999.tb09269.x

Swerdlow, N. R., and Geyer, M. A. (1993). Prepulse inhibition of acoustic startle in rats after lesions of the pedunculopontine tegmental nucleus. Behav. Neurosci. 107, 104-117.

Swerdlow, N. R., Paulsen, J., Braff, D. L., Butters, N., Geyer, M. A., and Swenson, M. R. (1995). Impaired prepulse inhibition of acoustic and tactile startle response in patients with Huntington's disease. J. Neurol. Neurosurg. Psychiatry 58, 192-200.

Swerdlow, N. R., Shoemaker, J. M., Bongiovanni, M. J., Neary, A. C., Tochen, L. S., and Saint Marie, R. L. (2007). Strain differences in the disruption of prepulse inhibition of startle after systemic and intra-accumbens amphetamine administration. Pharmacol. Biochem. Behav. 87, 1-10. doi: 10.1016/j.pbb.2007. 03.014

Takesian, A. E., Bogart, L. J., Lichtman, J. W., and Hensch, T. K. (2018). Inhibitory circuit gating of auditory critical-period plasticity. Nat. Neurosci. 21, 218-227.

Takeuchi, H., Iba, M., Inoue, H., Higuchi, M., Takao, K., Tsukita, K., et al. (2011). P301S mutant human tau transgenic mice manifest early symptoms of human tauopathies with dementia and altered sensorimotor gating. PLoS One 6:e21050. doi: 10.1371/journal.pone.0021050

Tekinay, A. B., Nong, Y., Miwa, J. M., Lieberam, I., Ibanez-Tallon, I., Greengard, P., et al. (2009). A role for LYNX2 in anxiety-related behavior. Proc. Natl. Acad. Sci. U. S. A. 106, 4477-4482. doi: 10.1073/pnas.0813109106

Tezcan, D., Tumkaya, S., and Bora, E. (2017). Reversal learning in patients with obsessive-compulsive disorder (OCD) and their unaffected relatives: is orbitofrontal dysfunction an endophenotype of OCD? Psychiatry Res. 252, 231-233. doi: 10.1016/j.psychres.2017.03.001

Towart, L. A., Alves, S. E., Znamensky, V., Hayashi, S., Mcewen, B. S., and Milner, T. A. (2003). Subcellular relationships between cholinergic terminals and estrogen receptor-alpha in the dorsal hippocampus. J. Comp. Neurol. 463, 390-401. doi: 10.1002/cne.10753 
van Enkhuizen, J., Milienne-Petiot, M., Geyer, M. A., and Young, J. W. (2015). Modeling bipolar disorder in mice by increasing acetylcholine or dopamine: chronic lithium treats most, but not all features. Psychopharmacology 232, 3455-3467. doi: 10.1007/s00213-015-4000-4

Vila-Ballo, A., Mas-Herrero, E., Ripolles, P., Simo, M., Miro, J., Cucurell, D., et al. (2017). Unraveling the Role of the Hippocampus in Reversal Learning. J. Neurosci. 37, 6686-6697. doi: 10.1523/JNEUROSCI.3212-16. 2017

Wan, F. J., and Swerdlow, N. R. (1997). The basolateral amygdala regulates sensorimotor gating of acoustic startle in the rat. Neuroscience 76, 715-724. doi: 10.1016/S0306-4522(96)00218-7

Wu, M., Puddifoot, C. A., Taylor, P., and Joiner, W. J. (2015). Mechanisms of inhibition and potentiation of alpha4beta2 nicotinic acetylcholine receptors by members of the Ly6 protein family. J. Biol. Chem. 290, 24509-24518. doi: 10.1074/jbc.M115.647248

Zhang, H., Kranzler, H. R., Poling, J., and Gelernter, J. (2010). Variation in the nicotinic acetylcholine receptor gene cluster CHRNA5-CHRNA3CHRNB4 and its interaction with recent tobacco use influence cognitive flexibility. Neuropsychopharmacology 35, 2211-2224. doi: 10.1038/npp.20 10.95
Conflict of Interest: JM was co-founder of Ophidion, Inc., a biotechnology company.

The remaining authors declare that the research was conducted in the absence of any commercial or financial relationships that could be construed as a potential conflict of interest.

Publisher's Note: All claims expressed in this article are solely those of the authors and do not necessarily represent those of their affiliated organizations, or those of the publisher, the editors and the reviewers. Any product that may be evaluated in this article, or claim that may be made by its manufacturer, is not guaranteed or endorsed by the publisher.

Copyright (๑) 2021 Sherafat, Chen, Lallai, Bautista, Fowler, Chen, Miwa and Fowler. This is an open-access article distributed under the terms of the Creative Commons Attribution License (CC BY). The use, distribution or reproduction in other forums is permitted, provided the original author(s) and the copyright owner(s) are credited and that the original publication in this journal is cited, in accordance with accepted academic practice. No use, distribution or reproduction is permitted which does not comply with these terms. 